\title{
再生波形解析による記録ノイズの検討
}

A study on recording noise with readback waveform analysis

\author{
是成貴弘、松寺久雄、坪井真三、田上勝通 \\ 日本電気(侏) 機能エレクトロニタス研究所
}

Takahiro Korenari, Hisao Matsutera, Shinzo Tsuboi and Katsumichi Tagami

Functional Devices Res. Labs. NEC Corp.

Abstruct

The recording noise of sputtered Co alloy media at high recording density was studied with readback waveform. High noise power of longitudinal recording media at high recording density was correlated to the fluctuation of magnetic transition region. In perpendicular recording media, in contrast, the fluctuation of magnetic transition region was small even at high recording density, which leads to low noise power.

Keywords: Magnetic recording, Recording media, Recording noise, Magnetic transition width, perpendicular recording

1.はじめに

長手記録媒体において、特にスパッタにより成膜し たCoCr系メ夕ル禁体においては、高密度記録時に低固 波数域に桇体ノイズが顕著となり、記録密度が高くな るにつれて増大する。一方、整直記録媒体においては 媒体ノイズが小さく、記録密度位存娄小さい。

長手記録媒体における記録ノイズは、主に磁化遙移 領域のジダザグ形状に由来していると考えられるが、 単純にジダザグ珢状加発生するのではなく、形状の ゆらざに起因していると考无られる”。しかし、この

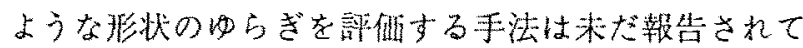

W.

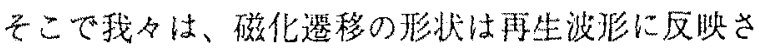
れ、形状のゆらぎも波帅に反欥されることに注目し、 雨生波形の解析をすることにより、磁化遷移の形状の

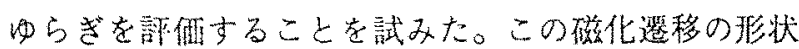

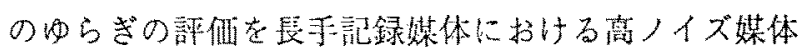

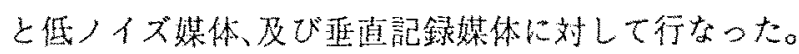

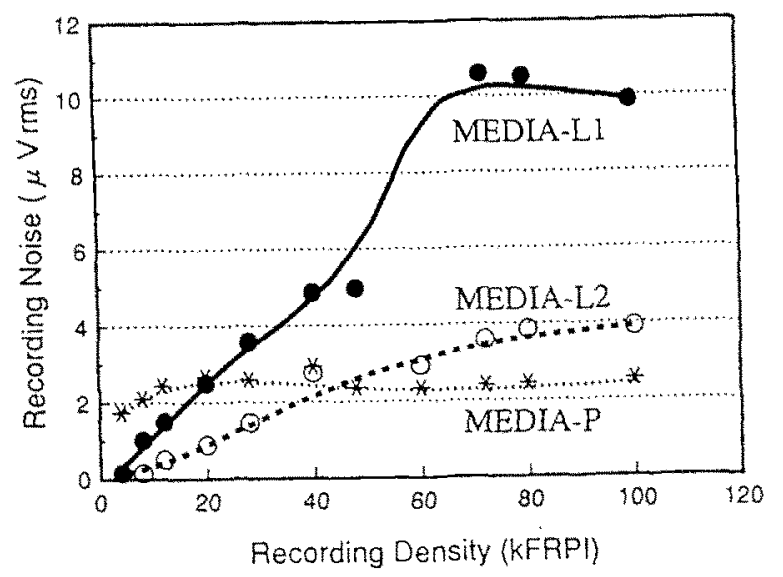

因1記録ノイズの記録密度依存性

表 1 媒体の磁気特性

\begin{tabular}{|c|c|c|c|c|}
\hline sample & Hc & Mr & $\delta$ & $S^{*}$ \\
\hline MEDIA-L1 & $13700 \mathrm{e}$ & $480 \mathrm{e} \mathbf{y} / \mathrm{cc}$ & $40 \mathrm{~nm}$ & 0.78 \\
\hline MEDIA-L2 & $13400 \mathrm{e}$ & $410 \mathrm{emu} / \mathrm{cc}$ & $40 \mathrm{~nm}$ & 0.76 \\
\hline MEDIA-P & $13500 \mathrm{e}$ & $90 \mathrm{enu} / \mathrm{cc}$ & $200 \mathrm{~nm}$ & - \\
\hline
\end{tabular}




\section{2. 試料の作製}

記録再生特性の評洒に用いた記録媒体は、長手記録 媒体として NiP/Al合金基板上にCr下地膜を $200 \mathrm{~nm}$ 、 $\mathrm{CoCrTa}$ 膜を $40 \mathrm{~nm} 、 \mathrm{C}$ 保護膜を $20 \mathrm{~nm}$ 成膜したものを用 いた。成膜の条作（成膜速度、成膜ガス压）を制御し てノイズ特性の巽なる(MEDIA-L1,MEDIA-L2)を作製 した。函直記録禁体としてはガラス基板上に加熱しな がら CoCrTa膜を200nm、C保護膜を20nm成膜したもの を用いた(MEDIA-P)。これらの媒体の䊅晶粒の孤立度 の語值（ঠＭプロット）はV S Mを用いて行なった。

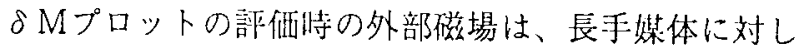
ては面内に、亟㨁媒体に対しては面に対して垂直方闹 に印加した。

それぞれの桇体の磁気特性（保磁力 H c、残留磁化 $\mathrm{Br}$ 、磁性膜厚 $\delta$ 、保磁加角型比 $\mathrm{S}^{\circ}$ )を表1に示す。 表中に示した $\mathrm{H} \mathrm{c}$ は、長手媒体に対しては面内保磁力、 进直桇体については膜面に刘して亚直方向の保磁力の 值を示している。長手媒体における面内の配向性は、 ヒスデリシス曲線からほとんど完全に分散していると 考えられる。

また、記録再生特性の評洒には、インダクティブ、 M R 複合型ヘッドを用いた。インダクティブヘッドの

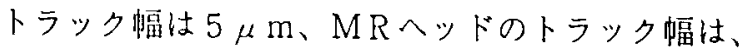

3.75 $7 \mathrm{~m}$ である。また、ヘッド媒体間のスペーシ

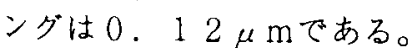

\section{3.ノイズ特性}

CoCrTa艮手記録媒体において、Cr下地膜と磁性膜の 成膜条件を制御し得られた高ノイズ媒体(MEDIA-L1) と低ノイズ媒体(MEDIA-L2)、及び聇直記録媒体

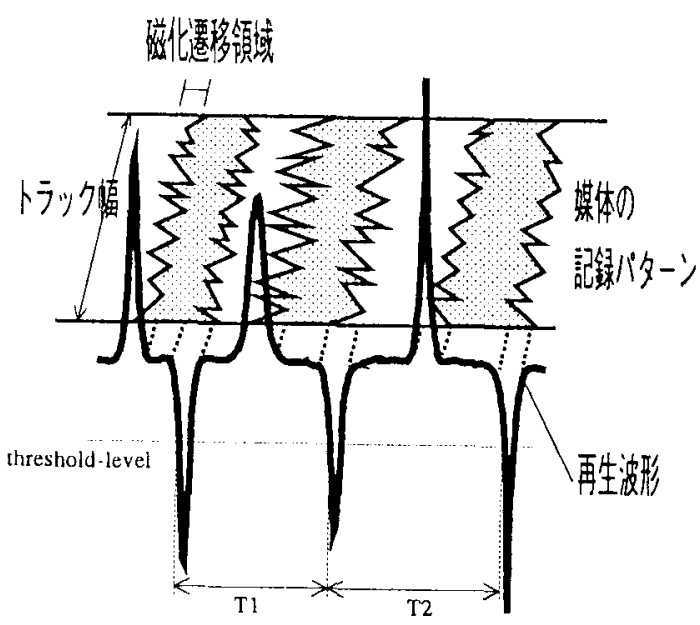

図3波形に反映される磁化遷移領域
(MEDIA-P)のノイズ特性を図1に示す。図に示したよ うに、長手記録媒体においては記録密度が高くなるに つれて記録ノイズが増大する。また、媒体の成膜条件 の違いでノイズ特性が罢なる。一方、䑤淔記録媒体に おいては高記録密度における記録ノイズが小さい。 表 2 には、それぞれの媒体のD 50 、S / N 等を示す。

表 2 媒体の記録再生特性

\begin{tabular}{|c|c|c|}
\hline Sample & $D_{60}$ & Media S/N \\
\hline MEDIA-LI & 50 KFRPI & $32.8 \mathrm{~dB}$ \\
\hline MEDIA-L2 & $50 \mathrm{kFRPI}$ & $36.3 \mathrm{~dB}$ \\
\hline MEDIA-P & $45 \mathrm{kFRPI}$ & $38.6 \mathrm{~dB}$ \\
\hline
\end{tabular}

(*) at 50kFRPI

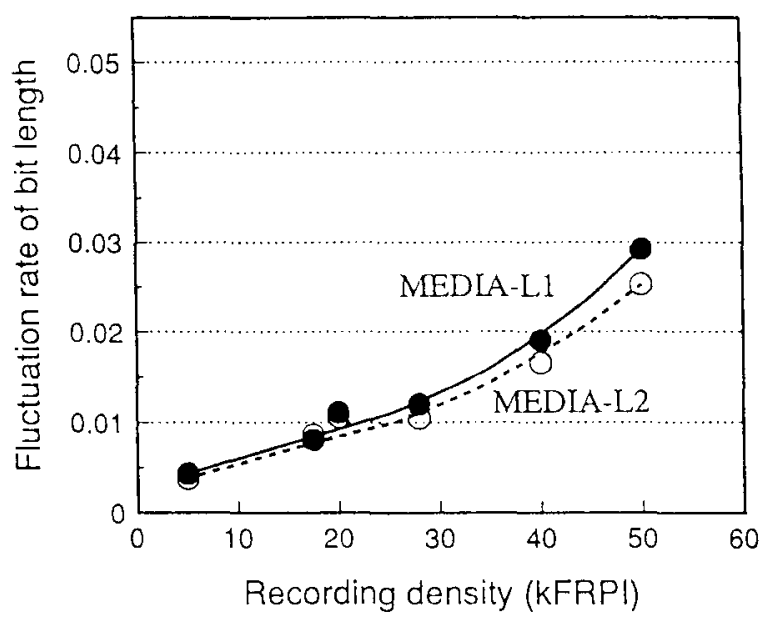

図 2 磁化遷移位置のゆらぎ

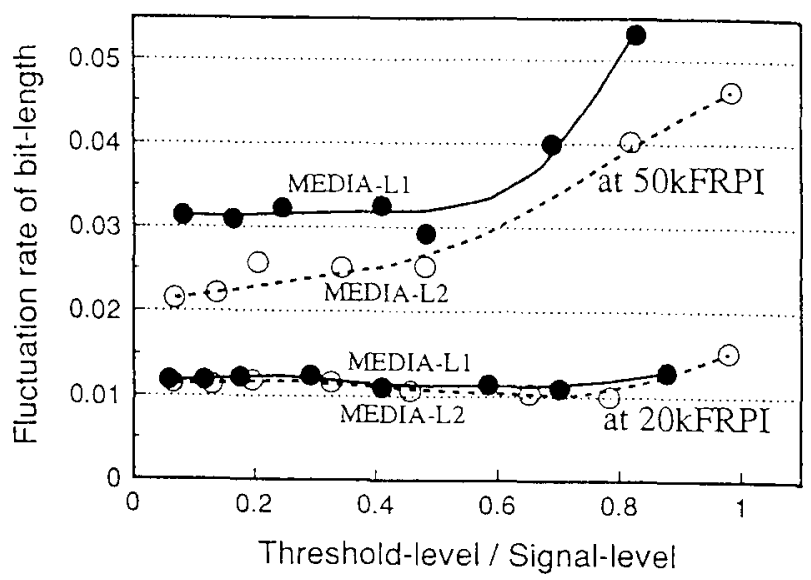

図4 磁化遷移の形状のゆらぎ 


\section{4.磁化遷移位置のゆらぎ}

記録ノイズの琹团として、磁化䢛移位置のゆらぎ( わゆるジッターと呼ばれているもの）が考えられる。 光磁気ディスクにおけるジッタ一は熱的な姴素によ るものであると考えられており、ランダム性を持つた めにキャりア周波数近傍にノイズが見られる。しかし、 磁気ディスクにおけるジッターは、磁気的な相互作朋 によって発生すると洘えられるため、その周期性に起 因して低周波数域にノイズが発生一ると考えられる。

磁化㹂移位置のゆらぎは、タイムインターバルアナ ライザにより評仙した。図2に長手記録媒体における 磁化邆移位犆のゆらぎ量の記録密度依存性を示す。横 軸は記録密度、縦軸はノイズと関係深いと考えられる ビット長で䙺格化したゆらぎの標準偏差值を表してい る。な扔、ビット長を規定する出力レベル(thresholdlevel) は、再生出力の1/2の点を用いた。この図か ら記録密度が高くなるにつれてビット長のゆらきが著 しくなっており、ノイズと強い相関があると考えられ る。しかし、高ノイズ媒体(MEDIA-L1)と低ノイズ媒体 (MEDIA-L2)を比較して、ほとんど差がなく、時系列に も差が見られないことから、臨移位置のゆらぎが 2 種 の媒体のノイズ特性の差の要因ではないと考えられ る。

\section{5. 磁化邆移領域の形状ゆらぎ}

次に、磁化選移領域の形状（磁化遷移幅等）のゆら ぎを評俔した。位置のゆらぎと同様に、形状のゆらぎ

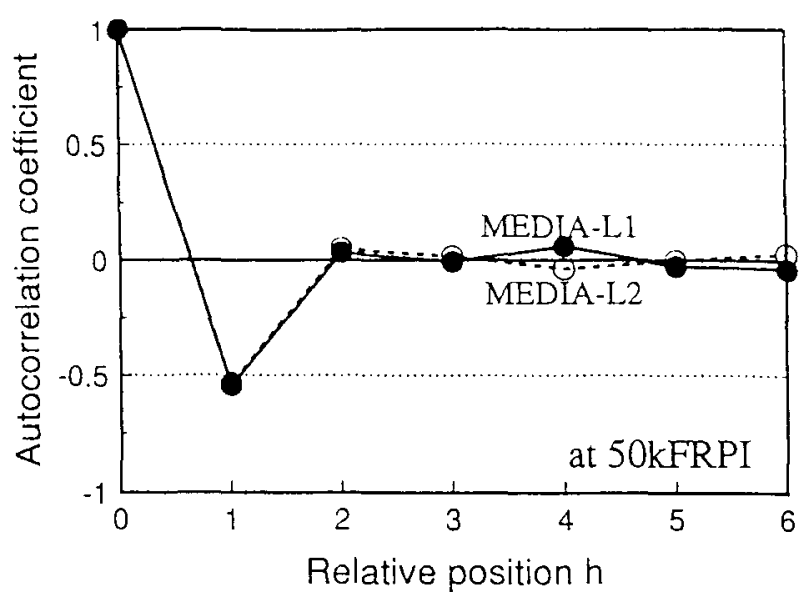

図 7 らぎの自己相関関数

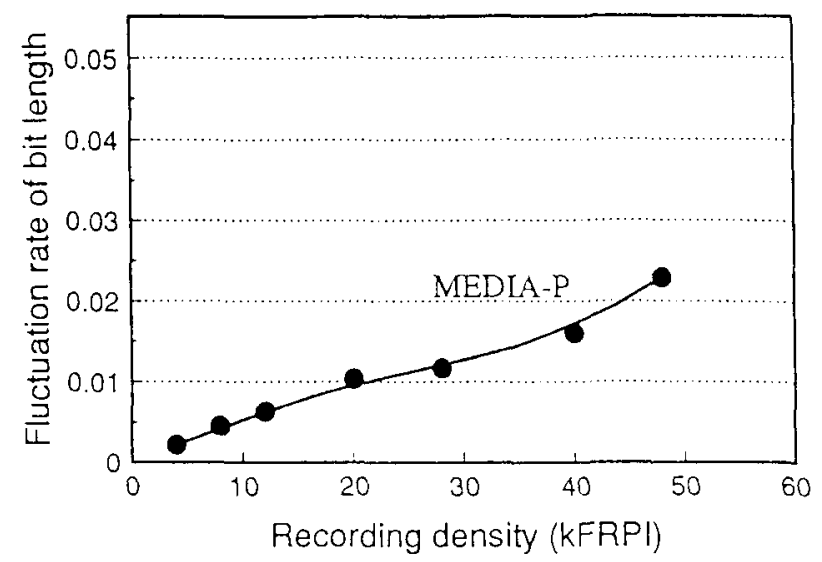

図 5 垂直媒体における磁化遷移位置のゆらぎ

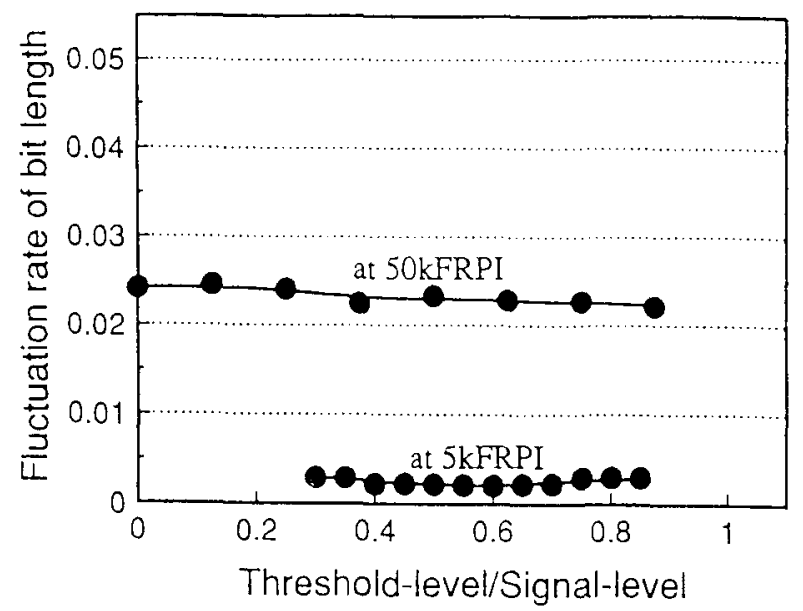

図 6 垂直媒体における磁化遷移形状のゆらぎ

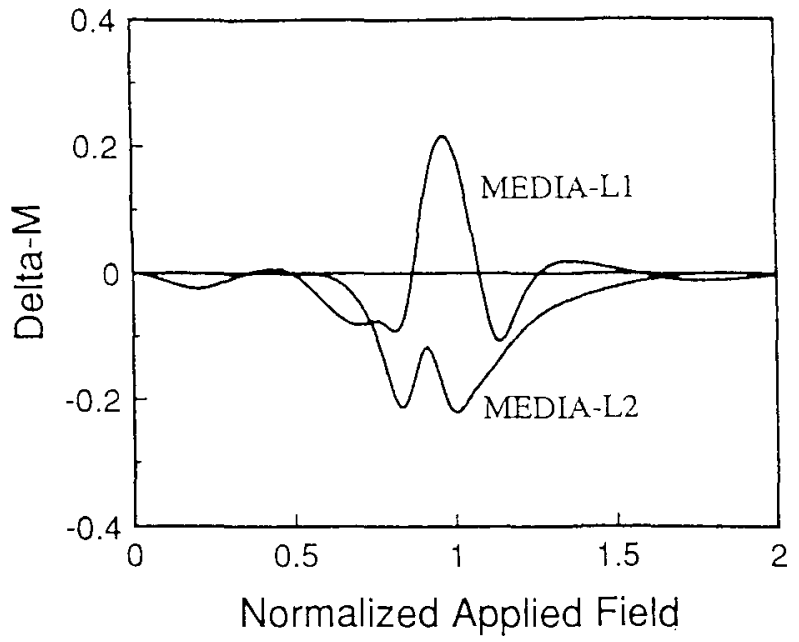

図 8 長手媒体における。Ｍプロット 
も再生波形に反映されるため（図３）、再生波形のゆら ぎを解析することにより磁化遷移の形状のゆらぎを評 仳した。

波形のゆらぎの評檤についても、タイムインターバ ルアナライザを用いた。ビット長を测定する際に threshold-levelt変化させて测定した場合、波形のゆ らぎが典ければthreshold-levelに刘しビット長のゆ らぎは一定であるはずである。つまり、thresholdlevelに対するゆらぎ量の変化が波形のゆらぎを表す と考えられる。

図4に前述の2種の媒体におけるビット長のゆらぎ の threshold-level依存性を示す。縦軸がゆらぎ量、横 軸は、threshold-levelを平均出力で規格化した量であ る。この結果、低密度記録時にはthreshold-levelに対 し、ビット長のゆらぎ量の変化ははとんどなく、波形 のゆらぎはほとんどないことがわかる。しかし、高密 度記録時にはthreshold-levelに対しゆらぎ量が顕著 に変化している。よって波諺にゆらぎがあり、磁化遷 移の形状にゆらぎがあることを示唆していると考えら れる。波形のゆらき（threshold-levelに対するゆらぎ の変化量）はMEDIA-L1とMEDIA-L2において違いが あり、形状のゆらぎの違いが長手記録媒体における高 密度記録時における記録ノイズの差の要因であると考 えられる。

一方、䍹直記録媒体における僄移位置のゆらぎを図 5 に示し、threshold-levelに対するビット長のゆらぎ の変化を図 6 に示す。図 5 より、瑇值記録媒体におけ る遷移位置のゆらぎは長手記録媒体とほほ同等であ る。しかし図 6 から、帮直記録媒体においては threshold-levelに対するゆらぎの変化がほとんどな く、磁化逿移の形状のゆらぎがほとんどないと考えら れる。これは、垂直記録媒体の記録ノイズが非常に小 さいことと対応している。

\section{6. 媒体の磁気特性とビット衰ゆらざの相関}

先に示したビット長のゆらざにおて、長手記録媒 体におけるビット長の時系列を解析した。図 7 にビッ ト長の自己相関関数を示寸。図に示したように隣接す るビット間に强い負の相関があることがわかり、光磁 気ディスクで見られるようなランダムなりらざではな く、周期性を持ったゆらぎであることがわかる。これ が低周波数域に記録ノイズが発生する所以であると考 えられる。ビット長のゆらぎに周期性があり、特に隣 接するビット間に強い相関があることから、ゆらぎに は磁気的な相互作用が强く関与していると考えられ る。つまり最近多く報告されているように媒体の結晶 粒間の磁気的相互作用を分断することで、ビット長の ゆらぎを少なくすることができノイズを低減すること

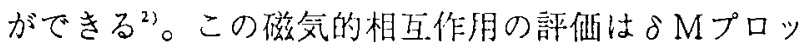
ドにより行なった。結舆を次節に示す。

\section{7. 結晶粒の磁気的孤立度の棓仙}

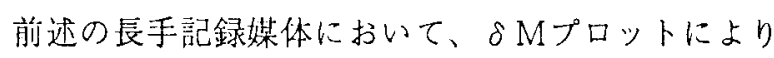
結晶粒の磁気的孤立度の評酸行なった結果を図 8 に 示す。横軸は残貿保磁力H rで䙺格化した印加磁場で

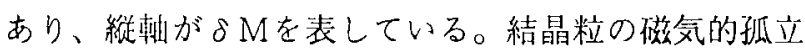

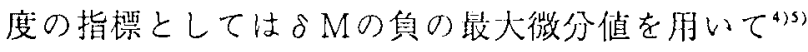
孤立度と記録ノイズの相関を㑉べた。

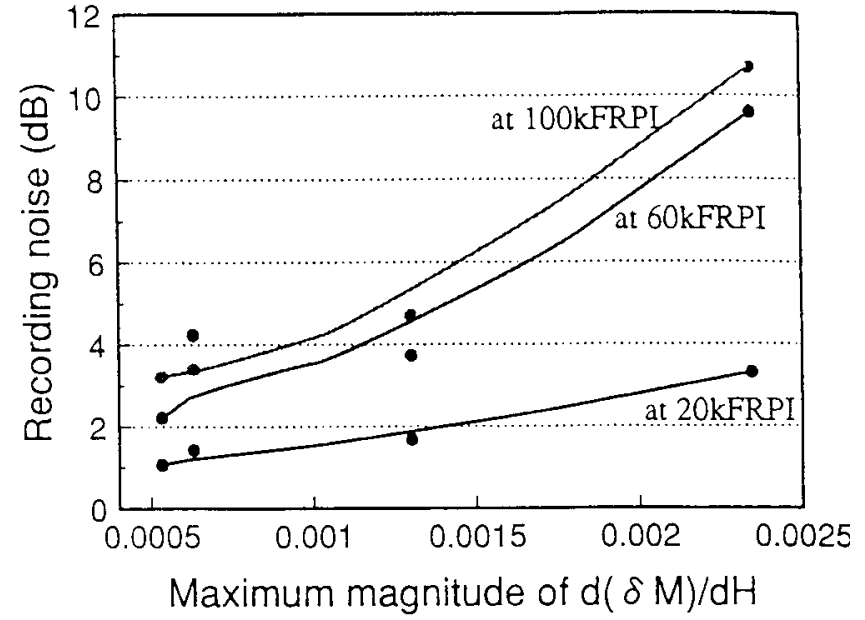

図 $9 \mathrm{CoCrTa}$ 長手記録媒体における $\delta \mathrm{M}$ とノイズの相関

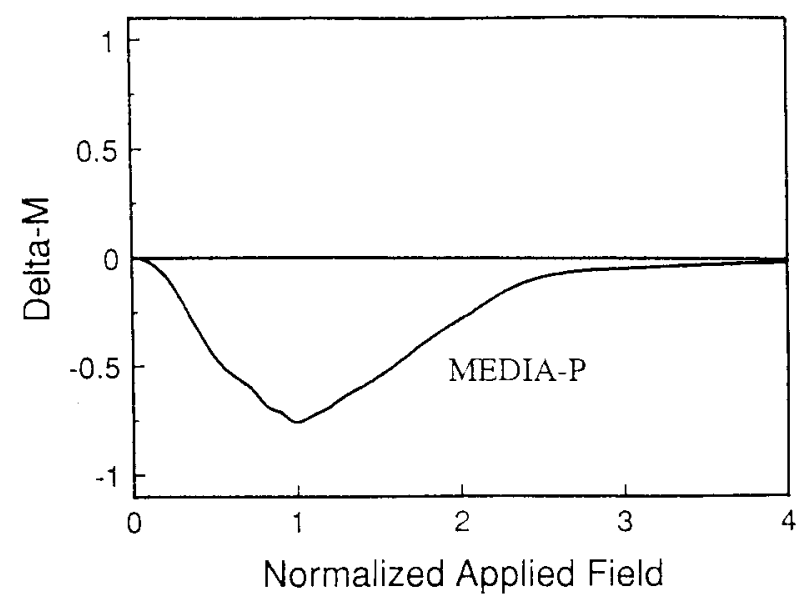

図 10 垂直媒体における $\delta$ Mプロット 
図 9 にCoCrTa/Cr長手媒体における $\delta \mathrm{M}$ と記録ノイ ズの相関を示す。 $\delta \mathrm{M}$ とノイズは正の相関を持ち、特 に高記録密度に扔いて相関が顕著になっている。これ は特に高記録密度において結晶粒間の交换相互作用の 分断が重要であることを示唆していると考えられる。

図 10 に韭昼禁体(MEDIA-P)に打忊る $\delta$ Mプロット を示す。本実験は漤体面に垂值に磁場を印加している ので反磁場の効果も含まれている。そこで反磁場の効 果を調べるために、媒体の異方性の分散が $3^{\circ} 、 5^{\circ}$ 、 $10^{\circ}$ の場合について、一様回転モデルにより $\delta \mathrm{M}$ 曲 線への反磁場の影響を計算した。結果は図 11 に示し ている。図で明らかなように、 $\delta \mathrm{M}$ 曲線に比べ反磁場 の影響は小さい。反磁場の影響は分散性が增すほど、 より小さくなる。

異方性の分敬を $5^{\circ}$ と仮定して、MEDIA-Pの $\delta$ M明 線を補正した結果を図 12 に示す。この結果、 $\delta \mathrm{M}$ 明 線はMEDIA-L2のようなW型を示す。しかし、反磁場 の效果は $\delta \mathrm{M}$ 曲線に比べさいため、 $\delta \mathrm{M}$ 曲線は磁場 に対して負の做となり、垂直媒体では結晶粒間の静磁 結合が大きいことを意味していると考えられる。辰 手記録媒体においては結晶粒問の静磁的な相互作用も ノイズ增大の要因となるが〉、西直記録媒体に扔いて は静磁結合が係化邆移の形状のゆらぎを小さくすると 考えられることから、今回用いた重直記録媒体の磁化 遷移形状のゆらざが小さいことと対応していると考え られる。

\section{8.まとめ}

長手記録媒体において高ノイズ媒体と低ノイズ媒体 を作製し、磁化迺移位置のゆらぎと磁化遷移の形状の ゆらぎを評価した。その結果、2種の媒体の記録ノイ ズ特性の違いの要因は、磁化選移位置のゆらぎではな

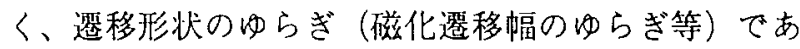
ると思われる。

一方、垂直記録媒体においては選移の形状のゆらぎ がほとんどなく、垂值記録媒体において記録ノイズが 非常に小さいことと対応している。

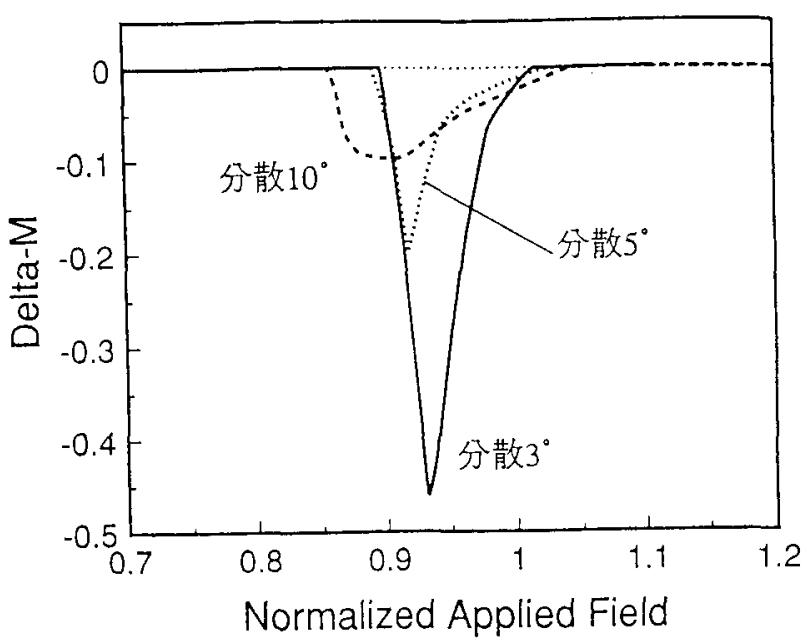

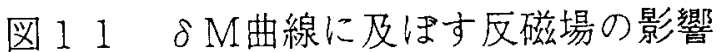

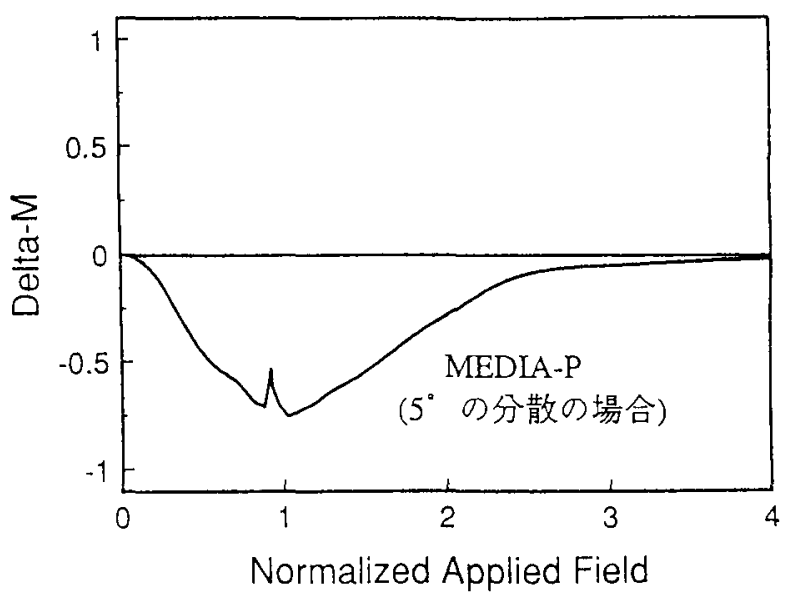

図 12 垂直媒体における (反磁場補正後)

文献

(1) J.G.Zhu and H.N.Bertram : IEEE Trans.Magn., MAG-24,2706(1988).

(2) T.Chen and T.Yamashita : IEEE Trans.Magn., MAG-24,2700(1988).

(3) P.E.Kelly et al. : IEEE Trans.Magn.MAG-25,3881 (1989).

(4) J.Heidmann et al.: J.Appl.Phys.69,7731(1991).

(5) M.Lu et al.: J.Mag.Soc.Jpn,15 Supp1.S2,945 (1991). 